\title{
Gestão de fragmentação no desmonte de rochas
}

\author{
Blasting fragmentation management: an \\ innovative approach using complexity analysis
}

\section{Jacopo Seccatore \\ Dipartimento del Territorio, dell 'Ambiente e delle Geotecnologie, \\ Politecnico di Torino, Italy \\ jacopo.seccatore@gmail.com \\ Giorgio de Tomi \\ Professor Associado, Escola Politécnica \\ da Universidade de São Paulo, Brazil \\ gdetomi@usp.br}

\section{Enrique Munaretti}

Professor Adjunto,

Escola de Engenharia,

Universidade Federal do

Rio Grande do Sul, Brazil

enrique@ufrgs.br

\section{Maurício Dompieri}

Mestrando, Escola Politécnica da Universidade de São Paulo, Brazil mdompieri@usp.br

\section{Resumo}

Esse trabalho descreve a pesquisa sobre a aplicação de análise de complexidade para avaliar o desempenho do processo de desmonte de rocha na mineração. $\mathrm{O}$ objetivo principal da pesquisa é o desenvolvimento de um método que permita identificar uma solução robusta para gerenciar a fragmentação do desmonte e para planejar o processo de forma a alcançar as metas de produtividade da britagem. A pesquisa utiliza ferramentas de análise de complexidade, introduzindo uma abordagem particular de sistemas complexos inédita em mineração e em aplicações de desmonte. Os resultados alcançados indicam que a compreensão adequada das correlações entre as variáveis-chaves no desmonte traz benefícios importantes para apoiar a tomada de decisão no ambiente de alta incerteza do processo de desmonte de rocha. A busca por um sistema robusto se mostrou mais relevante do que a busca por uma solução teoricamente ótima, já que os níveis de robustez e de complexidade podem ser utilizados para comparar diferentes modelos e para medir a aderência desses modelos aos dados de campo.

Palavras-chave: Perfuração e desmonte; fragmentação de rocha; análise de complexidade, análise de robustez.

\begin{abstract}
The paper describes the research carried out in the application of complexity analysis in order to evaluate the performance of the rock blasting process in mining. The main objective of the research is the development of a new method to allow the identification of a robust solution for managing rock fragmentation and to plan the process so that productivity targets can be achieved. The research uses complexity analysis tools introducing a particular approach for complex system analysis in mining and in rock blasting. The results indicate that the proper understanding of the correlations between the key-variables in blasting provides important benefits in the decision making process in the highly uncertain environment of rock blasting. The search for a robust system has proven to be more relevant than the search for a theoretically optimum solution, as the levels of robustness and complexity can be used to compare different models and to measure the adherence of such models to the actual field data.
\end{abstract}

Keywords: Drilling and blasting, rock fragmentation, complexity analysis, robustness analysis. 


\section{Introduction}

Rock fragmentation by blasting is a fundamental procedure in the mining process. It is higly related to the performance of subsequent operations, from loading equipment wear through comminution and processing costs to the final customer's requirements. It has been observed in many case studies (Sastry \& Chandar, 2004; Ryu et al., 2009; Clerici \& Mancini et al., 1974) that the energy consumption of mucking and crushing depends directly upon the blast fragmentation. Even though primary blasting costs can be reduced by a coarser fragmentation output (Ryu et al., 2009), in general, poor fragmentation leads to the following situations (Bozic 1998, Sastry \& Chandar 2004, Ryu et al. 2009, Clerici \& Mancini et al. 1974, Mansfield \& Schoeman 2010,

\section{Complexity analysis}

The blasting process in open pit mining incorporates several variables that can contribute to its fragmentation results. Such variables have been discussed by many authors (Lu \& Latham, 1998; Thornton et al., 2002; Mancini \& Cardu, 2001; Chakraborty et al., 2004.) following a general classification that includes: I) geometrical variables (drilling pattern and bench geometry); II) explosive variables; III) initiation system variables; and IV) rock parameters. This paper presents a new approach to understand the interdependencies among all these variables through Complexity Analysis tools. In this heuristic procedure, where neither ap-

\section{Complexity and fragility}

Highly complex systems are more exposed to the effects of uncertainty because of the countless ways by which they can fail, some of them even due to apparently innocent causes. Complexity derives from the design, while uncertainties derive from

\section{Optimization and robustness}

The approach to this problem by searching for the optimum appears to be inefficient. As specified in the introduction, the geological environment is characterized by too many uncertainties to have
Scott, 1996):

- Increased secondary blasting.

- Decreased rate of muck shovel loading.

- Increased difficulty in transportation.

- Increased energy consumption at crushing or milling.

- Increased vibrations and noise to neighborhood.

- Unsafe situation and damage to equipment when handling oversize material.

- low crusher and mill performances

Secondary blasting should be avoided as much as possible, as it decreases the productivity by moving equipment and people to a safe place. This situation can be interpreted as "rework" which generally means high costs for a low production. McKenzie (1967) showed how increasing rock fragmentation decreases loading,

proximation nor linear regression models are applied to the data, it is possible to take into account the a-typical set of data usually considered as outliers. It results in an innovative methodology: the whole complexity of the given system is captured, revealing hidden structural links that would be necessarily by-passed through a traditional linear-regression based analysis, in the form of a system map.

Engineering systems can be seen as transformations of input data into elaborated output results through particular types of flow. The complexity $C$ is a function of the structure and the entropy of the data flowing through the

the realization and the work environment. Their combination leads to the fragility of the system. In this case study, the design is the blast project, totally controllable; the realization is the drilling and charging operations, only controllable up to a certain hauling and crushing costs, while drilling and blasting costs increase; an optimum situation should be found at the intersection of McKenzie costs curves. One important challenge is the high degree of uncertainty posed by local geological conditions. In practical situations, due to structural conditions (Grenon et al., 1998; Lu \& Latham, 1998, Chakraborty et al., 2004), the cost curves, and hence the optimum conditions, vary from bench to bench. Nevertheless, aiming at industrial level productivity, a robust pre-defined blast design must be used to drive the subsequent operations, with minimal adjustments if any. This paper proposes an innovative approach to the solution of the blasting problem, as an alternative to conventional optimization approaches.

system. Moreover, every system has a critical level of complexity $C_{C R}$, in which proximity it starts to behave erratically and in an unpredictable way. The degree of Robustness, or resilience, defined as the difference between $C$ and $C_{C R}$, is the measure of the system's ability to withstand changes in its working environment without losing functionality. Thus, a system is considered "robust" if its results are not greatly affected by pathologic input data. Further elaboration on Complexity Analysis is beyond the scope of this paper. A more detailed reading on the subject can be found in Marczyk (2006) and Marczyk (2008).

\section{Model Analysis}

The reliability of a model can be

an optimum valid for many applications. Robustness is the capability of the system to produce expected and acceptable results under varying or even unforeseen conditions. Since the geology varies from site to level; the environment is the local geological condition, not controllable. Since uncertainty in the environment (geology) cannot be avoided, we must learn to live with it. Hence the need is to manage complexity through the design (blast project). site, and often from bench to bench on each site, setting a robust method can grant better overall results in varying environments, lowering the costs and increasing benefits such as predictability and safety. 
complexity of the system. A measurement of the reliability (credibility) of a model can be given by the Model Credibility Index (Marczyk, 2008): .

\section{Complexity analysis application}

The proposed approach has been applied to actual blasting data of a limestone quarry located in Taubaté, São Paulo, in Brazil. In order to evaluate the impact of Complexity Analysis, the first approach has been the determination of the levels

\section{Empirical model}

The model used by the mine management to dimension the blast is based on an empirical procedure. It refers to the monomial formula: $Q=P . F . \times H \times E \times V$, where $Q$ is the quantity of explosive per hole, P.F. is the powder factor, or specific charge, $H$ is the height of the bench, $E$

\section{Analytical model}

Berta (1985) wrote a blast design model based on a total energetic balance of

the blast. According to Berta, the expression of the specific charge can be written

$$
\text { P.F. }=\frac{s . \varepsilon_{s s}}{\eta_{1} \cdot \eta_{2} \cdot \eta_{3} \cdot \varepsilon}
$$

Where $s$ is the desired degree of fragmentation, $\varepsilon_{\mathrm{ss}}$ the rock specific surface energy, $\varepsilon$ the explosive specific energy, $\eta_{1}$ an acoustic transfer efficiency taking into account the acoustic impedances of the rock and the explosive, $\eta_{2}$ a

coupling efficiency taking into account the backlash between the cartridges and the hole wall, and $\eta_{3}$ an energetic fragmentation transfer efficiency considered as 0,15 as Berta analytically demonstrates that the amount of en-

$$
V=\varnothing_{c} \sqrt{\frac{\rho_{e} \pi}{4 . P . F .}}
$$

Berta usually suggests a squared drilling pattern, hence considering $\mathrm{E}=$

\section{Mine site data}

The mine extracts limestone by open pit blasting of horizontal benches and sub-vertical holes. Depending on
In the present case, test refers to real measurements from the field. Generphysics; if $C_{\text {test }}<C_{\text {model }}$ the Model gener-

of complexity in the dimensioning of the geometrical and charging parameters of To achieve this analysis three modeling instances have been evaluated:

i) the empirical dimensioning model used

the spacing between the holes and $V$ the burden. All the geometrical variables of the blast, including stemming and subdrilling, are correlated by empirical thumb charge is empirically determined. The ally, if $C_{\text {test }}>C_{\text {model }}$ the Model misses
V. Known the height of the bench $\mathrm{H}$, the charge per hole $\mathrm{Q}[\mathrm{kg}]$ is therefore calcu- the zone of the quarry, the rock appears to be from compact to quite weathered. The data used in this analysis are taken ates noise. A model is a well-done one when its MCI is low, and both System Maps have the same topology (same connections between the variables). by the mine management.

ii) An analytical dimensioning model proposed by Berta (1985).

iii) The field data of drilling pattern and charging used in the mine during blasting operations in March 2010. mine management refers it to the mass of the rock instead of its volume, and considers two different conditions: Massive Rock (150 200 g/t) and Weathered Rock $(80 \sim 120 \mathrm{~g} / \mathrm{t})$. The charge of explosive per hole is consequently calculated knowing the volume weight of the rock $\rho_{\mathrm{R}}\left[\mathrm{t} / \mathrm{m}^{3}\right]$.

as follows:

ergy transferred to the rock to produce fragmentation is $15 \%$ of the total. The burden can then be calculated after the diameter of the cartridge $\varnothing_{c}$, the specific charge and the density of the explosive $\rho_{\mathrm{e}}$ :

lated using again the monomial formula reported in the previous paragraph. from the field reports compiled by the blasters and referring to the drilling pattern and charging parameters used on the field.

\section{Complexity analysis on the empirical model}

The empirical model shows such a high degree of empiricism that at this stage no correlations appear between the geometrical characteristics of the pattern $(\mathrm{V}, \mathrm{S}, \mathrm{B}, \mathrm{U})$ and the charging parameters (P.F., Q). These results are shown in Figure 1a. The P.F. is mainly determined by the weathering condition of rock, being calculated around two central values for massive or weathered rock. That creates two attractors shown in the multidimensional map of Figure $1 \mathrm{~b}$ (specific charge P.F. Vs the charge per hole Q), which cannot be explained anywhere else in the model. This means that, according to complexity, this kind of modeling cannot be based on theoretical proceedings without calibrating the specific charge with tests, in order to artificially create the missing links through field tests.

Since the drilling parameters have no significant connection with the blasting variables, they have been deleted 


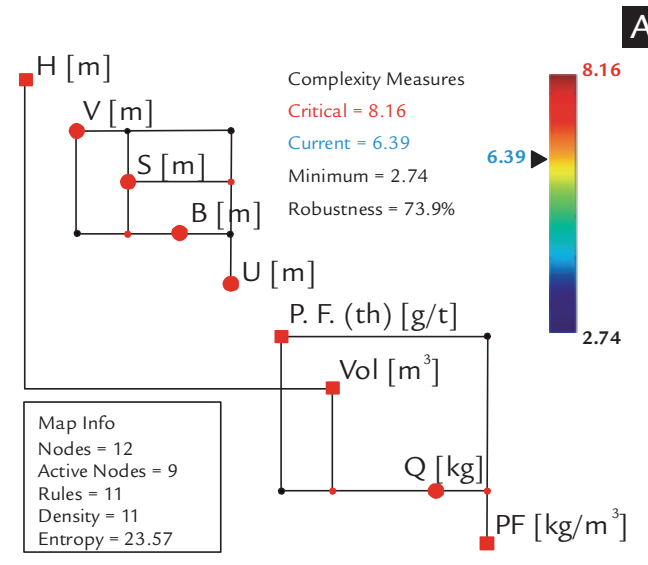

to consider a simplified datasheet that takes into account only the height of the bench and the P.F. as inputs and the charge per hole as a result.

It can be concluded that:

- It is necessary to calibrate the P.F.

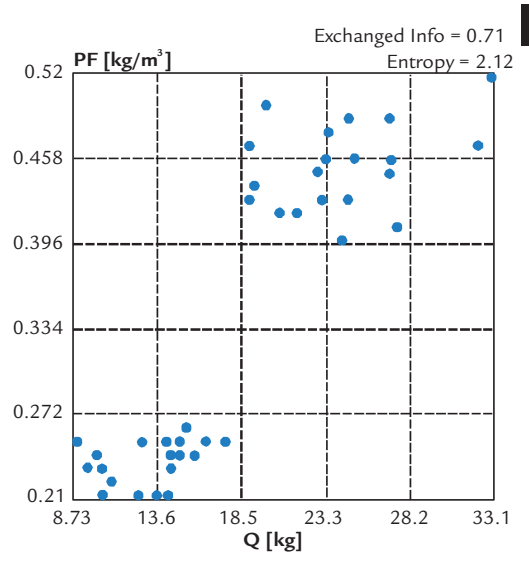

with test blast at the beginning of excavations.

- Robustness is artificially high, due to the hard coded analytical geometric relationships of the model that add structure to the system and increases
Figure 1

System process map

a) and scatter plot

b) of P.F. of the empirical model.

global entropy due to additional information exchange.

- In this kind of modeling the height of the bench doesn't influence the complexity of the determination of the result (charge per hole).

\section{Complexity analysis on the analytical model}

Berta's model contains many more variables than available at this stage of the analysis. Missing values of geomorphological variables have been taken from literature suggested by Berta himself to simulate the local conditions of the limestone orebody. The energetic and acoustic values of the explosive, where not available, have been assumed to be the same of similar emulsion explosives. The choice of the specific values, anyhow, doesn't affect the behavior of the model.

Complexity Analysis performed on this model shows that the variables appear to have a high degree of inter-correlation, notable by the number of links of Figure 2. Connections appear redundant, and this contributes to increase complexity. On the other hand, the model's level of complexity is very close to the critical level (see the rainbow column in Figure 2) hence the system appears to be very
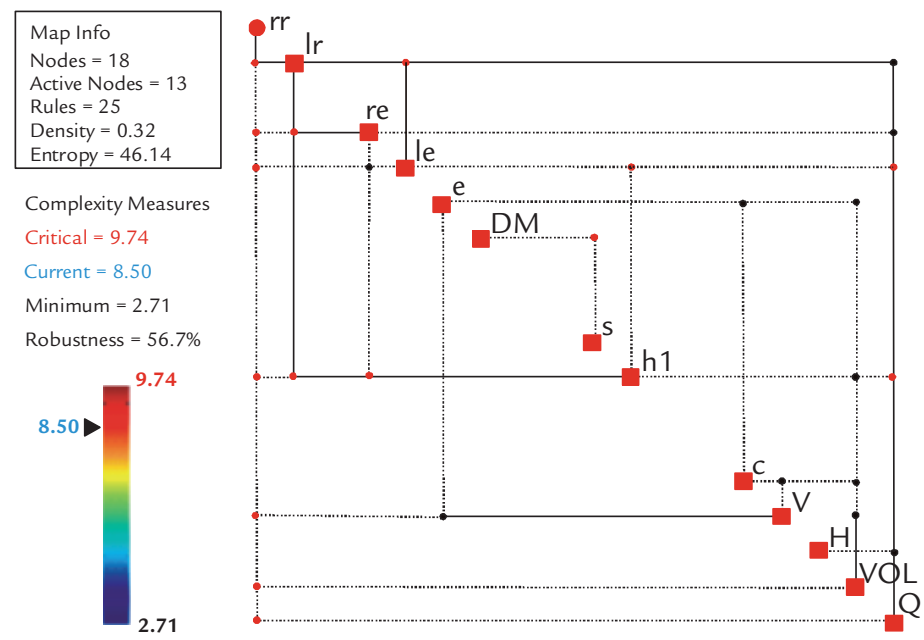

fragile. The model has a low level of confidence. This means that the model might be able to generate inconsistent results if fed with a high number of highly varying inputs.

It can be concluded that:

- The system appears fragile, close to its critical level of complexity.

- The variables appear strongly intercorrelated and their inter-connections redundant.

Figure 2

System process map of Berta's model.

\section{Complexity analysis on the mine site data}

Complexity Analysis performed on the mine site data, as illustrated in Figure 3 , shows the structural links between geometrical and charging parameters that were lacking in the empirical model, as indicated in section 3.4. The complexity of this amount of data appears considerably low, and very far from its level of criticality.

It can be concluded that in this kind of open pit bench blasting:

- The large dimension of the bench to be blasted (number of rows $x$ total length of the blast) greatly contributes to the complexity of the operations.

- The number of rows influences the charging parameters, confirming what is suggested by many authors (e.g. Mancini \& Cardu, 2001) to vary the P.F. for the holes of the rows after the first one.

- The degree of complexity of this kind of working appears to be very low and far away from its criticality. 
Figure 3

System process map and Complexity profile of field data.

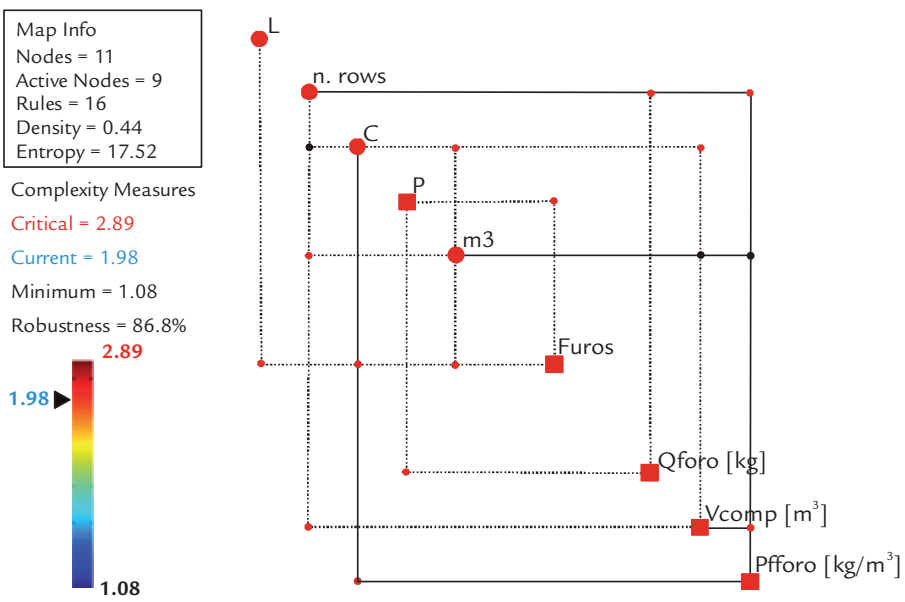

\section{Comparison of the models}

A comparison has been carried out on the level of complexity of these two extremely different approaches to blast design. The results, reported in Table 1 , indicate that the analytical approach,

Table 1

Comparison between the complexity levels of the analyzed models. with a greater number of active nodes, links and rules, appears to be more affected by complexity. On the other hand, the parameter that mostly contributes to complexity appears to be much more critical for the empirical model than in analytical model.

In this case, the Empirical Model appears more robust, while the analytical one is more suitable for optimization.

\begin{tabular}{c|c|c}
\hline Complexity Parameters & $\begin{array}{c}\text { Empirical Model } \\
\text { (Mine Management) }\end{array}$ & $\begin{array}{c}\text { Analytical Model } \\
\text { (Berta) }\end{array}$ \\
\hline Complexity Level C & 6.39 & 8.50 \\
\hline Critical Complexity $C_{\mathrm{CR}}$ & 8.16 & 9.74 \\
\hline Robustness & 73.90 & 56.70 \\
\hline $\begin{array}{c}\text { Maximum Contribution to complexity } \\
\text { of the most critical parameter }\end{array}$ & $25.03 \%$ & $16.95 \%$ \\
\hline
\end{tabular}

\section{Comparison between the empirical model and the site data}

Table 2 presents a summary comparison between the empirical model and the actual site data collected during drilling and charging. The complexity of the empirical model is much higher than the complexity of the field data. This appears to be due to the high dependency on the geometrical

Table 2

Comparison between the complexity levels of the model and the field data.

\section{Conclusions}

In the proposed approach, searching for the optimum appears to be inefficient for a high productivity target. The geological environment is characterized by too many uncertainties to have an optimum point valid for different blasting scenarios. Researching for robustness in blast design appears to correlation of the drilling pattern. On the other hand, simplifying the datasheet to the essential variables (height of the bench and pre-determined P.F.) produces a degree of complexity which appears to be very close to the complexity of the field data.

From the point of view of Complex- ity Analysis, the drilling and the charging are separated and independent characteristics of the blast. In both cases the model depends largely on the determination of P.F. This increases the complexity of the model, and it generates noise that requires further calibration to be eliminated.

\begin{tabular}{c|c|c|c}
\hline Complexity Parameters & Empirical Model & Mine Site Data & $\begin{array}{c}\text { Simplified Data } \\
\text { Empirical Model }\end{array}$ \\
\hline Complexity Level C & 6.39 & 1.98 & 2.12 \\
\hline Critical Complexity $C_{\mathrm{CR}}$ & 8.16 & 2.89 & 2.56 \\
\hline Robustness & 73.90 & 86.80 & 70.30 \\
\hline
\end{tabular}

produce much more efficient results.

Complexity Analysis allows a clear understanding of the correlations between the variables in blasting systems and helps to manage their robustness.

Robustness and complexity levels can be used to compare different models and to measure the fitting of models with field data.

Complexity Analysis allows the understanding of the behavior of critical variables that can generate instability in the system thus leading to unexpected results. 


\section{References}

BERTA, G. Explosive, a working tool. Milano: Italesplosivi int. editions, 1985. 479 p. BOŽIC, B. Control of fragmentation by blasting. Rudarsko-geoloiko-nafini zbornik, Zagreb, v. 10, p. 49-57, 1998.

CLERICI, C., MANCINI, R. et al. Blasting operations in quarry. Mutual influence between blasting and fragmentation. In: CONGRESS ON ORNAMENTAL STONES AND INDUSTRIAL MINERALS MINING, 1. Proceedings... Torino: Politecnico di Torino, 1974.

CHAKRABORTY, A.K. et al. Parametric study to develop guidelines for blast fragmentation improvement in jointed and massive formations. Engineering Geology, n.73, p. 105-116, 2004.

GRENON, M., HADJIGEORGIOU, J., LIU, Q. Quantifying in-situ rock block size and resulting fragment size distributions due to blasting. FRAGBLAST, n.2, p. 205-218, 1998.

LU, P., LATHAM, J. P. A model for the transition of block sizes during fragmentation blasting of rock masses. FRAGBLAST, n.2, p. 341-368, 1998.

MACKENZIE, A. S. Optimum blasting. In: ANNUAL MINNESOTA MINING SYMPOSIUM, 28. Proceedings... Duluth, MN, pp. 181-188, 1967.

MANCINI, R., CARDU, M. Rock excavations: the explosives. Benevento: Hevelius editions, 2001. $295 \mathrm{p}$.

MARCZYK, J. Measuring and Tracking Complexity. In: INTERNATIONAL CONFERENCE ON COMPLEX SYSTEMS, 6. Proceedings... Boston: New England Complex Systems Institute, 2006.

MARCZYK, J. Practical complexity management. Trento: Uni Service editions, $2008.258 \mathrm{p}$.

MANSFIELD, S., SCHOEMAN, J. L. Blasting solutions for rapid mine expansion. In: ANNUAL CONFERENCE INTERNATIONAL SOCIETY OF EXPLOSIVES ENGINEERS, 36. v. 1, G, 2010.

RYU, D. W., SHIM, H. J., HAN, C.Y., AHN, S. M. Prediction of rock fragmentation and design of blasting pattern based on 3-D spatial distribution of rock factor. International journal of rock mechanics and mining sciences, v. 46, n. 2, p. 326332, 2009.

SASTRY, V., CHANDAR, K. Influence of the initiation system on blast results: case studies. Fragblast, n.8, p. 207- 220, 2004.

SCOTT, A., (Ed.), Open pit blast design: analysis and optimization. Brisbane: The University of Queensland, Julius Kruttschnitt Mineral Research Centre (JKMRC), 1996. 338p.

THORNTON, D., KANCHIBOLTA, S. S., BRUNTON, I. Modeling the impact and blast design variation on blast fragmentation. The International Journal for Blasting and Fragmentation, Swets and Zeitlinger, The Netherlands, v. 6, n. 2. p. 171$172,2002$.

Artigo recebido em 22 de outubro de 2010. Aprovado em 28 de julho de 2011. 